\title{
Kajian Sensory/Panca Indra pada Interior Bangunan Heritage Kafe di Surabaya
}

\author{
Jessica Astrie Gunawan ${ }^{1}$, Sherly de Yong ${ }^{2}$, Anik Rakhmawati ${ }^{3}$ \\ 1,2,3 Universitas Kristen Petra \\ jesicca.astried@gmail.com ${ }^{1}$, sherly_de_yong@petra.ac.id ${ }^{2}$,nikarakhma@gmail.com ${ }^{3}$
}

\begin{abstract}
ABSTRAK
Kafe Tanamera merupakan bangunan cagar budaya/heritage dimana memiliki nilai sejarah. Pengalaman panca indra masih kurang diperhatikan oleh desainer maupun pihak kafe. Efek sensorik pada manusia dan lingkungan sangat penting dalam mendesain elemen-elemen pada interior ruang. Indra penglihatan secara umum memiliki peranan yang paling dominan dalam interior, namun indra non-visual kurang diperhatikan. Rangsangan 4 panca indra yaitu pendengaran, penciuman, peraba, dan penglihatan memberi pengaruh emosional dalam pengalaman ruang. Pengalaman ruang sangat penting dalam mempertahankan ketertarikan pengunjung. Tujuan penelitian ini adalah untuk memahami pentingnya penerapan teori sensory/panca indra pada elemen interior bangunan heritage kafe Tanamera. Metode penelitian yang digunakan adalah kualitatif-kuantitatif deskriptif dengan acuan dasar teori Joy Monice M dan Vodvarka dalam buku Sensory Design serta Xue Yu. Berdasarkan analisis yang telah dilakukan, maka dapat disimpulkan bahwa pengalaman panca indra memiliki peran penting bagi manusia dalam mempersepsi ruang. Pengalaman yang melibatkan panca indra dapat diterapkan pada 9 elemen interior. Secara keseluruhan, kafe Tanamera terdapat beberapa pengalaman yang melibatkan panca indra pada elemen interior ruang. Pengunjung kafe Tanamera yang merasakan beragam pengalaman melalui penerapan elemen interior, yaitu elemen enviroment, space, light, decoration, groundplane, enclosure, support, display, information.
\end{abstract}

Kata kunci: panca indra; indra; pengalaman ruang; 9 elemen interior; interior

\section{ABSTRACT}

Tanamera cafe is a heritage building culture/heritage which has historical value. Sensory experience is still less noticed by the designer or the cafe. Sensory effects on humans and the environment is very important in the design elements in the interior space. The sense of sight generally has a dominant role in the interior, but the non-visual senses less attention. 4 sensory stimuli that hearing, smell, touch, and sight emotional influences in the experience of space. The experience of space is crucial in maintaining the interest of visitors. The purpose of this study was to understand the importance of applying the theory of sensory / senses the interior elements of heritage buildings Tanamera cafe. The method used is qualitative-quantitative baseline descriptive theory of Joy Monice $M$ and Vodvarka in the book Sensory Design and Xue Yu. Based on the analysis that has been done, it can be concluded that sensory experience has an important role for human perception of the space. Involving sensory experience can be applied to the interior of the 9 elements. Overall, the cafe Tanamera there are some experiences that involve the senses in interior elements of space. Tanamera coffee drinkers who feel the diverse experience through the application of interior elements, namely element enviroment, space, light, decoration, groundplane, enclosure, support, displays, information.

Keyword: five sense; sensory; space experience; 9 interior elements; interior

\section{PENDAHULUAN}

Ruang merupakan fasilitas berjalannya aktivitas manusia, dimana dalam melakukannya harus memberikan kenyamanan. Ketika berbicara mengenai ruang, manusia cenderung merespon atau berpersepsi. Menurut Itellson \& Prohansky (1970), persepsi lingkungan merupakan proses yang melibatkan komponen kognitf (berpikir), afektif (emosional), 
interpretative, dan evaluative yang berhubungan dengan panca indra (Herliana, 2016:124). Menurut Floor, bahwa konsumen menikmati dan terinspirasi oleh berbagai pengalaman lingkungan yang unik, pengalaman yang ada tersebut masuk melalui 4 panca indra (Wulandari, 2014:85). Efek sensorik pada manusia dan lingkungannya sangat penting dalam mendesain interior, yaitu aspek bau, pendengaran, haptic, hampir tidak dianggap dalam mendesain. Menurut Schmitt, panca indra dimanfaatkan secara maksimal dapat menigkatkan kenyamanan, serta daya Tarik bagi konsumen (Noviarini, 2014:4).

Aspek visual dalam mendesain menjadi hal yang lebih dominan, yaitu cahaya, material, warna, bentuk, serta ukuran. Menurut Pallasma, kecenderungan dimana penglihatan dianggap sebagai fokus utama dalam desain. Indra penciuman, peraba, pendengaran memiliki peranan penting juga yang dimiliki manusia. Aspek sensory/panca indra seharusnya dapat menjadi acuan bagi seorang desainer dalam merancang interior. Menurut Lindstrom penerapan sensory/panca indra dapat memotivasi perilaku pembelian konsumen, memicu minat mereka dan memungkinkan respon emosional yang mendominasi pemikiran rasional mereka.

Bangunan heritage atau bangunan cagar budaya di kota Surabaya sangat banyak peninggalannya dengan memiliki berbagai fungsi. Terdapat banyak bangunan heritage yang di alih fungsi menjadi bangunan kafe. Dengan semakin berkembangnya perekonomian kota Surabaya, semakin meningkat juga aspek bisnis kuliner yang berkembang pesat Kafe memiliki posisi bagi masyarakat Surabaya mulai dari kaum anak muda hingga orang dewasa. Kafe menjadi lifestyle bagi semua kaum pada jaman sekarang ini, manusia selalu bersosialisasi atau berinteraksi satu sama lain. Kaum anak muda banyak memanfaatkan kafe sebagai tempat bersosialisasi serta memanfaatkan waktu luang. Kaum dewasa pun ikut serta dalam memanfaatkan kafe sebagai tempat bersosialisasi dengan rekan kerja, serta menjadi tempat meeting.

Tren coffe shop yang semakin menjamur menjadi gaya hidup kota Surabaya. Kafe Tanamera merupakan coffee shop yang berada pada bangunan cagar budaya, dengan memiliki suasana ruang yang nyaman dengan konsep heritage. Ketika konsumen memasuki sebuah ruangan, penting untuk memberikan kesan secara emosional dengan penyajian ruangan yang menarik dan unik, memberikan kesan yang akan selalu diingat oleh konsumen. Konsep old trend is the new trend merupakan konsep yang bagus dan menarik untuk dapat dijadikan tema dalam kafe, tentunya akan menjadikan kafe memiliki daya Tarik sendiri untuk para konsumen. Penelitian tentang panca indra untuk bangunan heritage belum benar-benar diterapkan dalam mendesain, sehingga dengan memaksimalkan pengalaman sensory/panca indra dalam atmosfer kafe dapat menciptakan kenyamanan dan meningkatkan daya Tarik yang ingin dikunjungi secara berulang.

\section{METODE PENELITIAN}

Penelitian ini menggunakan metode kualitatif-kuantitatif deskriptif. Metode deskriptif pada penelitian ini berguna untuk menganalisa, mendeskripsikan atau menjelaskan secara jelas bagaimana implementasi panca indra pada interior cafe. Metode deskriptif ini juga menginterpretasikan kondisi pengalaman panca indra yang terjadi pada beberapa titik yang akan dianalisa.

Menurut Sugiyono $(2013,13)$ mengatakan penelitian kuantitatif adalah penelitian dengan memperoleh data yang berbentuk angka dan data kualitatif yang diangkakan. Metode ini merupakan metode analisis dengan melakukan perhitungan yang bersifat sebagai pembuktian dari masalah. Metode kuantitatif ini menganalisa hasil kuisioner konsumen dengan menggunakan angka, yang berguna sebagai pendukung pada analisa data lapangan. 
Penelitian ini menggunakan teknik pengumpulan data dengan cara mengkaji teori literatur yang berkaitan dengan panca indra interior kafe yang dapat dijadikan sebuah acuan landasan kegiatan penelitian ini, observasi pada kafe Tanamera Surabaya, pengukuran layout lapangan, wawancara dengan memberikan beberapa pertanyaan kepada supervisor kafe Tanamera untuk mendapatkan informasi langsung mengenai kafe Tanamera

Bhattacherjee (2012:74) bahwa kuisioner merupakan instrumen yang digunakan untuk mengumpulkan data yang berisi serangkaian pertanyaan yang diisi oleh responden. Kuisioner ini bertujuan untuk memperkuat informasi wawancara dan juga mendapatkan data yang memiliki validitas yang tinggi. Metode kuisioner ini dilakukan pada pengunjung kafe Tanamera. Peneliti melakukan olahan data kuisioner dengan dangkakan menggunakan aplikasi yang berupa data, bertujuan untuk memperkuat data analisa data analisa data observasi. Serta melakukan dokumentasi yang digunakan pada penelitian ini berupa foto, serta video mengenai suasana kafe Tanamera

\section{HASIL PENELITIAN DAN PEMBAHASAN}

Peneliti melakukan analisa tolak ukur teori dengan menggunakan metode kritik deskriptif, analisa ini menggunakan acuan dasar teori dari Dak Kopec dalam buku Enviromental Psychology for Design $2^{\text {nd }}$ Edition, Malnar dan Vodvarka dalam buku Sensory Design, Xue Yu dalam jurnal Sensory Study in Restaurant Interior terkait panca indra dan batasan aspek interior yang ditangkap oleh panca indra, dan dilanjutkan dengan pembuatan tabel sebagai tolak ukur penerapan batasan panca indra pada 9 elemen interior.

Penulis melakukan analisa data berdasarkan proses pengolahan data lapangan yang diperoleh dengan teknik observasi di kafe Tanamera. Data observasi dijelaskan dalam bentuk paragraph kritik deskriptif dan kemudian disimpulkan dalam bentuk tabel mengenai terapan sensory pada elemen interior. Pengolahan data lapangan ini dianalisa per aspek panca indranya sesuai dengan titik sudut oandang hasil observasi Tanamera, serta penggunaan skema slider sensory dapat membantu analisis selai dengan penjabaran berupa paragraf.

Malnar dan Vodvarka (2004) menggunakan skema slider sensorik untuk menggambarkan sejauh mana kejelasan angka untuk menganalisa panca indra. Analisa terapan teori di komparasi dengan hasil analisis data lapangan dalam bentuk paragraf deskriptif dibantu dengan tabel kesimpulan. Kemudian peneliti melakukan pengolahan data kuisioner yang diberikan kepada pengunjung. Penarikan hasil perhitungan kuisioner pengalaman panca indra pengunjung dapat membantu hasil analisis.

\section{A. Analisa Tolak Ukur Teori}

Acuan dasar ini dapat mempermudah serta mengidentifikasi 9 elemen interior yang dirasakan menurut 4 paca indra, penglihatan, pendengaran, penciuaman, dan peraba. Teori Malnar dan Vodvarka dalam buku Sensory Study in Restaurant Interior menjelaskan mengenai panca indra dan batasan aspek yang ditangkap oleh panca indra. Beberapa aspek penerapan teori panca indra terkait dengan 9 elemen interior berupa tabel kesimpulan. 
Jessica Astrie Gunawan, Sherly de Yong, Anik Rakhmawati

Kajian Sensory/Panca Indra pada Interior Bangunan Heritage Kafe di Surabaya

Tabel 1. Tabel Kesimpulan Teori

\begin{tabular}{|c|c|c|c|c|}
\hline No & Sensory & $\begin{array}{l}\text { Aspek Batasan } \\
\text { yang Diterima } \\
\text { Sensory }\end{array}$ & Teori & $\begin{array}{c}\text { Elemen Interior } \\
\text { yang } \\
\text { Terpengaruh } \\
\end{array}$ \\
\hline \multirow[t]{4}{*}{1} & \multirow[t]{4}{*}{ Visual } & Ornamen & $\begin{array}{l}\text { Memberikan dekorasi detail pada } \\
\text { ruangan interior memberikan } \\
\text { kesan yang menarik, Dak Kopec } \\
\text { (2012). Ornamen memberikan } \\
\text { fungsi vital yaitu untuk } \\
\text { mengidentifikasi ruang, fungsi } \\
\text { social dan budaya, dan } \\
\text { mengirimkan identitas kepada } \\
\text { pengunjung, Joy Monice Malnar., } \\
\text { Frank Vodvarka (2004, 174) }\end{array}$ & $\begin{array}{l}\text { Enviroment, } \\
\text { space, } \\
\text { groundplane, } \\
\text { support, display, } \\
\text { decoration. }\end{array}$ \\
\hline & & Pencahayaan & $\begin{array}{l}\text { Pencahayaan sinar matahari dapat } \\
\text { mempengaruhi secara fisik dan } \\
\text { psikologis, Francis DK Ching., } \\
\text { Corky Binggeli ( } 2012,16) \text {. } \\
\text { Pencahayan alami membuat rasa } \\
\text { lelah yang berkuang dan } \\
\text { meningkatkan fokus, Maas, } \\
\text { Jayson, dan Klelber (1974, 524- } \\
\text { 526). }\end{array}$ & Space, light. \\
\hline & & Warna & $\begin{array}{l}\text { Warna memiliki banyak efek } \\
\text { psikologi yang memiliki persepsi } \\
\text { sendiri. Frank Mahnke H., Rudolf } \\
\text { H. Mahnke (1993) }\end{array}$ & $\begin{array}{l}\text { Decoration,Space, } \\
\text { environment, } \\
\text { light,Information, } \\
\text { Ground Plane, } \\
\text { Enclosure, } \\
\text { Support, Display. }\end{array}$ \\
\hline & & Kompleksitas & $\begin{array}{l}\text { Kompleksitas mengacu pada } \\
\text { keunikan elemen. Kompleksitas } \\
\text { dan misteri berhubungan dengan } \\
\text { presepsi masyarakat pada ruang } \\
\text { interior dan dapat mempengaruhi } \\
\text { preferensi. Scott (1993, vol. } 19)\end{array}$ & $\begin{array}{l}\text { Groundplane, } \\
\text { decoration, } \\
\text { display, support. }\end{array}$ \\
\hline & & Misteri & $\begin{array}{l}\text { Misteri merupakan sejauh mana } \\
\text { orang tertarik untuk mencari } \\
\text { informasi lainnya agar dapat } \\
\text { melangkah lebih jauh ke sebuah } \\
\text { ruang. Beberapa pendekatan } \\
\text { seperti menerapkan jarak pandang } \\
\text { yang pendek agar menarik dan } \\
\text { dari segi desain pintu masuk harus } \\
\text { menarik agar membuat } \\
\text { pengunjung tertarik untuk masuk. } \\
\text { Scott (1993, vol. 19) }\end{array}$ & $\begin{array}{l}\text { Space, } \\
\text { information,light. }\end{array}$ \\
\hline
\end{tabular}




\begin{tabular}{|c|c|c|c|c|}
\hline No & Sensory & $\begin{array}{l}\text { Aspek Batasan } \\
\text { yang Diterima } \\
\text { Sensory }\end{array}$ & Teori & $\begin{array}{c}\text { Elemen Interior } \\
\text { yang } \\
\text { Terpengaruh } \\
\end{array}$ \\
\hline \multirow[t]{2}{*}{2} & \multirow[t]{2}{*}{ Penciuman } & $\mathrm{Bau}$ & $\begin{array}{l}\text { Bau dapat mempengaruhi persepsi } \\
\text { rasa. Joy Monice Malnar., Frank } \\
\text { Vodvarka }(2004,42)\end{array}$ & Enclosure. \\
\hline & & Aroma & $\begin{array}{l}\text { Penelitian } 2014 \text { yang dilakukan } \\
\text { Andreas Keller dari Universitas } \\
\text { Rockefeller memperkirakan } \\
\text { bahwa manusia dapat mengenali } \\
\text { lebih dari } 1 \text { Trilliun bau yang } \\
\text { berbeda. Presepsi dan interpretasi } \\
\text { dipetakan terhadap aroma } \\
\text { tersebut, berikut dipetakan } \\
\text { presepsi dan interpretasi aroma } \\
\text { berdasarkan segmentasinya. } \\
\text { Menurut Juhani Pallasma, aroma } \\
\text { tertentu membuat kita tanpa sadar } \\
\text { mengingat kembali ruang yang } \\
\text { sepenuhnya telah dilupakan oleh } \\
\text { ingatan retina/ penglihatan. (2012, } \\
\text { 54) }\end{array}$ & $\begin{array}{l}\text { Enclosure, } \\
\text { decoration. }\end{array}$ \\
\hline \multirow[t]{2}{*}{3} & \multirow[t]{2}{*}{ Pendengaran } & Kebisingan & $\begin{array}{l}\text { Menurut Jaynes, suara adalah hal } \\
\text { yang paling mengontrol dari } \\
\text { semua akal mood kita. } \\
\text { Pengalaman auditori yang paling } \\
\text { penting yang diciptakan adalah } \\
\text { ketenangan. Juhani Pallasma } \\
(2012,51)\end{array}$ & $\begin{array}{l}\text { Ground plane, } \\
\text { Enclosure, } \\
\text { support. }\end{array}$ \\
\hline & & $\begin{array}{l}\text { Background } \\
\text { Musik }\end{array}$ & $\begin{array}{l}\text { Lingkungan tanpa suara } \\
\text { merupakan lingkungan yang tak } \\
\text { bernyawa dan nyata, tanpa adanya } \\
\text { aliran atau irama. Douglas Pocock } \\
(1989,194)\end{array}$ & Support, space. \\
\hline \multirow[t]{3}{*}{4} & \multirow[t]{2}{*}{ Peraba } & $\begin{array}{l}\text { Material dan } \\
\text { Tekstur }\end{array}$ & $\begin{array}{l}\text { Sensasi sentuhan merangsang } \\
\text { aktivitas otak, dapat dikatakan } \\
\text { bahwa perkembangan anak-anak } \\
\text { diaktifkan oleh sentuhan. Nuansa } \\
\text { ruangan sangat penting dalam } \\
\text { membentuk persepsi pengunjung } \\
\text { (Lindstorm vol.15) }\end{array}$ & $\begin{array}{l}\text { Decoration,Space, } \\
\text { environment, } \\
\text { light,Information, } \\
\text { Ground Plane, } \\
\text { Enclosure, } \\
\text { Support, Display. }\end{array}$ \\
\hline & & Suhu & $\begin{array}{l}\text { Pengaturan suhu ruangan atau } \\
\text { sirkulasi udara, kelembapan, dan } \\
\text { ventilasi juga mempengaruhi } \\
\text { pengalaman panca indra peraba. } \\
\text { Juhani Pallasma }(2012,56)\end{array}$ & Enclosure, space. \\
\hline & & $\begin{array}{l}\text { Dimensi Ruang, } \\
\text { tangga, dan } \\
\text { permukaan lantai } \\
\text { tidak rata }\end{array}$ & $\begin{array}{l}\text { Jarak memberikan kesadaran } \\
\text { sensorik. Jalur tangga melangkah } \\
\text { naik turun memberikan perasaan } \\
\text { tertentu, serta dengan permukaan } \\
\text { lantai yang tidak rata dapat } \\
\text { meningkatkan kesadaran sensorik. } \\
\text { Joy Monice Malnar., Frank } \\
\text { Vodvarka }(2004,50)\end{array}$ & $\begin{array}{l}\text { Space, ground } \\
\text { place, Enclosure. }\end{array}$ \\
\hline
\end{tabular}

Sumber: Diolah dari berbagai sumber (2020) 


\section{B. Analisa Hasil Pengambilan Data Lapangan}

Peneliti melakukan analisa data berdasarkan hasil observasi data lapangan pada titik yang telah ditentukan. 8 titik sudut pandang pada gambar 1 yang merupakan sudut optimal keseluruhan kafe untuk analisa menggunakan paragaraf deskriptif. Lokasi setiap titik tersebut, teras kafe tanamera dengan titik sudut pandang $\mathrm{A}$, daerah ruang makan 1 yang memiliki dua titik sudut pandang yaitu B dan C, area VIP dengan titik sudut pandang D, area makan 2 dengan titik sudut pandang $\mathrm{E}$ dan $\mathrm{F}$, area akhir yaitu smoking area dengan titik sudut pandang $\mathrm{G}$ dan H. Analisa data lapangan ini juga menggunakan skema slider Joy Monice Malnar dan Frank Vodvarka. Slider ini bertujuan untuk menjelaskan nilai tinggi hingga rendah, pengalaman panca indra yang dirasakan pada area tersebut, kotak merah indikator mendeskripsikan nilai sensory visual, pendengaran, penciuman, peraba yang dirasakan.

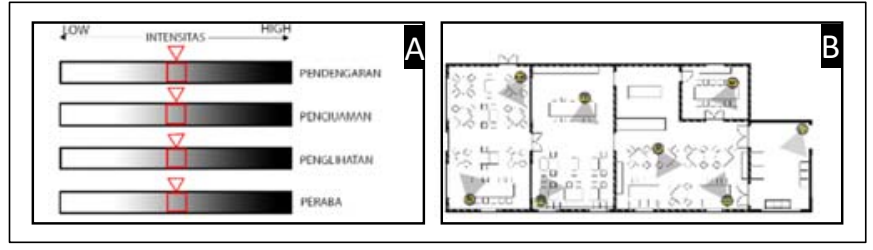

Gambar 1. Titik Sudut Pandang (A), Skema Slider Sensory (B) Sumber: Dokumentasi Penulis (2020)

\section{Pengalaman Sensory/Panca Indra Penglihatan}

Pengalaman aspek visual ini yang diterapkan pada elemen interior memiliki batasan aspek yaitu ornamen, cahaya, warna, kompleksitas, dan misteri. Peneliti menganalisa pengalaman panca indra pada tiap titik sudut pandang, pada setiap titik kafe Tanamera telah menerapkan ornamen khas yang terlihat pada gambar 1 yang diterapkan pada elemen interior yang berbedabeda. Titik A, C, G, H telah menerapkan pencahyaan pada berbagai elemen interior area kafe. Aspek pencahayaan pada titik D, E, F menggunakan pencahyaan lampu buatan dengan warna warm white dan cahaya alami yang kurang didapatkan pada area ini dan penggunaan warna yang gelap pada plafon sesuai gambar 3 membuat suasana ruang semakin gelap dan mempengaruhi pengalaman sensory pengunjung.

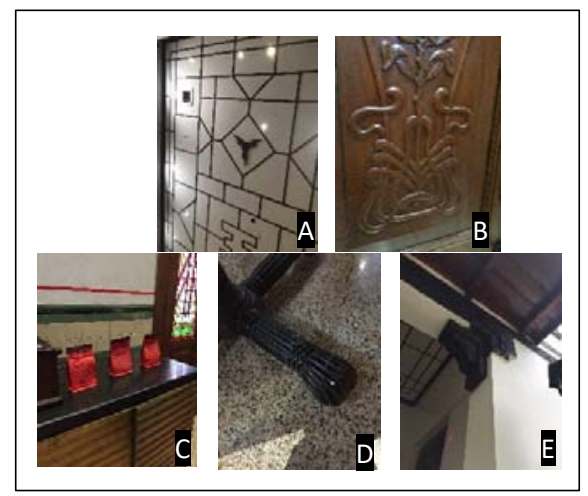

Gambar 2. Elemen Groundplane (A) (B), Decoration (c), Support (D), Space (E) Sumber: Dokumentasi Penulis (2020) 


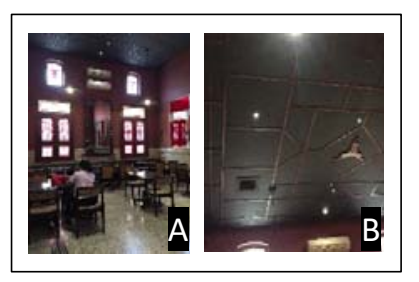

Gambar 3. Warna Dinding (A), Plafon (B)

Sumber: Dokumentasi Penulis (2020)

\section{Pengalaman Sensory/ Panca Indra Penciuman}

Indra penciuman salah satu pengalaman panca indra yang perlu diterapkan pada elemen interior. Aspek penciuman ini terdiri dari bau dan aroma. Kafe Tanamera pada area makan 1 dengan sudut pandang $\mathrm{C}$ memiliki aroma yang khas yaitu aroma kopi, yang memberikan memori bagi pengunjung dan kenyamanan. Sedangkan pada titik B, D terdapat bau makanan yang tidak dominan, akan tetapi dapat meningkatkan nafsu makan pengunjung.

Titik E dan F kurang mengatur kelembapan area tersebut, akan tetapi titik E yang berada dekat dengan dapur ini terdapat bau makanan yang dominan, sedangkan titik F ini merasakan bau furniture lama karena kelembapan ruang yang kurang diatur. Pada area smoking tidak terdapat aroma khas yang dirasakan karena sirkulasi udara yang kurang baik sehingga bau rokok yang mejadi dominan pada titik $\mathrm{G}$ dan $\mathrm{H}$.

\section{Pengalaman Sensory/Panca Indra Pendengaran}

Kafe Tanamera ini sendiri memerlukan pengalaman panca indra pendengar yang memiliki teori aspek batasan, yaitu kebisingan, dan background musik. Tanamera telah menerapkan beberapa aspek pada titik sudut pandang, titik C, E, F, G, H yang dapat dirasakan melalui penerapan speaker dan pengaturan dimensi ruang dan elemen groundplane yang membuat pengunjung dapat mendengarkan dengan jelas musik slow. Penggunaan musik ini memberikan suasana ruang kepada pengunjung

Titik A dan D masih belum terdapat background musik, hal ini membuat pengunjung yang berfokus pada kebisingan yang ada pada titik A yang berasal dari museum House of Sampoerna karena area teras yang terbuka dan berada dekat museum, sedangkan titik B terdapat kebisingan suara pengunjung lainnya yang berasal dari ruang makan 1 yang dapat menganggu kenyamanan aktivitas pengunjung.

\section{Pengalaman Sensory/Panca Indra Peraba}

Tanamera banyak menerapkan elemen-elemen interior yang merangsang indra haptic/peraba dengan aspek batasan, yaitu material dan tekstur, suhu, dimensi ruang. Yang pertama telah diterapkan pada elemen interior kafe Tanamera dengan penerapan material yang bervariasi dan memiliki tekstur pada semua titik sudut pandang kafe. Pengalaman panca indra peraba yang diterapkan pada area teras dengan penggunaan pintu kafe yang menggunakan cara unik ketika membuka pintu sesuai pada gambar 4. Penerapan tangga ketika memasuki area teras.

Elemen dekorasi berupa aneka jenis produk kopi dan dekorasi kuno pada area teras, area makan 1 dan area makan 2 membuat pengunjung dapat menyentuh produk yang meningkatkan pengalaman panca indra peraba. Pengaturan suhu pada titik $\mathrm{G}$ dan $\mathrm{H}$ yang terlalu dingin memngurangi pengalaman pengunjung, serta titik $\mathrm{H}$ berada dekat dengan jalur menuju kamar mandi hal ini menganggu aktivitas yang berada pada titik tersebut. Serta titik E yang letaknya 
dekat dengan dapur yang merupakan jalur staf kafe menganggu aktivitas terkait jarak privasi pengunjung yang terganggu. Area VIP yang merupakan area privasi dalam pengaturan jarak privasi dan dimensi ruang yang diberikan masih belum ada pengaturan sehingga area VIP yang dapat dilihat dari titik sudut pandang pada area makan 1. Hal ini dapat mengurangi pengalaman indra peraba pengunjung.

\section{Hasil Analisa Data Lapangan}

Analisa yang telah dilakukan di setiap titik sudut pandang kafe tanamera berkaitan dengan presepsi rangsangan indra pada penerapan elemen interior ruang. Pada titik A bagian teras kafe menerapkan pengalaman panca indra visual, dan peraba sesuai dengan gambar 4. Aspek panca indra visual yaitu, ornamen, pencahayaan, warna, kompleksitas, dan misteri. Pada segi aspek panca indra penciuman dan pendengaran masih belum terdapat penerapan. Sedangkan panca indra peraba telah menerapkan pada batasan material dan tekstur, suhu, dimensi ruang, tangga, dan permukaan lantai.

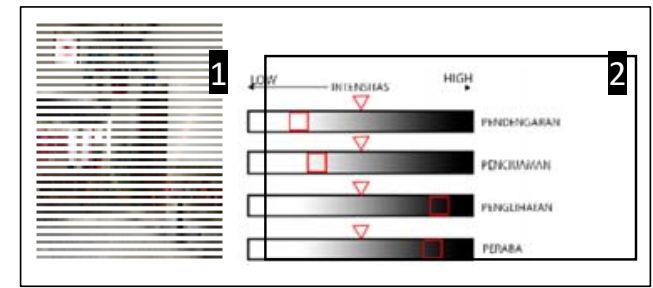

Gambar 4. Perspektif Area (1), Skema Slider Sensory yang Dirasakan di Titik A (2) Sumber: Dokumentasi Penulis (2020)

Kemudian ketika memasuki ruangan kafe Tanamera terdapat ruang makan 1 yang memiliki 2 sudut pandang yaitu $\mathrm{B}$ dan $\mathrm{C}$ yang dirasakan berbeda beda pengalaman panca indra penglihatan, penciuman, pendengaran dan peraba sesuai gambar 5. Ruang makan 1 telah menerapkan 5 batasan aspek panca indra visual yaitu, ornamen, pencahayaan, warna, kompleksitas, dan misteri. Aroma dan latar belakang musik yang dipersepsikan oleh panca indra penciuman dan pendengaran. Ruangan ini juga menerapkan batasan aspek material dan tekstur, suhu, dimensi ruang yang merupakan aspek batasan panca indra peraba.

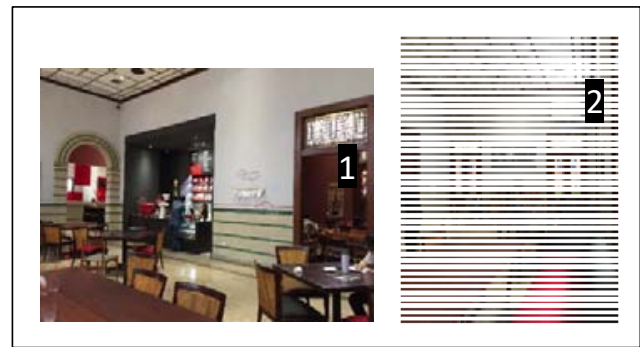

Gambar 5. Perspektif Area Titik C (1), Titik D(2) Sumber: Dokumentasi Penulis (2020)

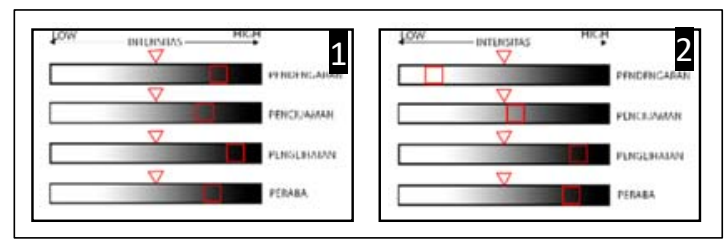

Gambar 6. Skema Slider Sensory yang Dirasakan di Titik B (1), Titik C (2) Sumber: Dokumentasi Penulis (2020) 
Area VIP berada pada ruangan setelah memasuki kafe Tanamera dengan titik sudut pandang $\mathrm{D}$ dapat merasakan pengalaman panca indra sesuai gambar 6, tempat tersebut menerapkan panca indra visual dengan batasan aspek yang dimiliki yaitu, ornamen, dan kompleksitas. Material dan tekstur, dan suhu yang merupakan batasan aspek panca indra peraba yang diterapkan pada ruangan ini. Akan tetapi aspek panca indra penciuman dan pendengaran masih belum diterapkan.

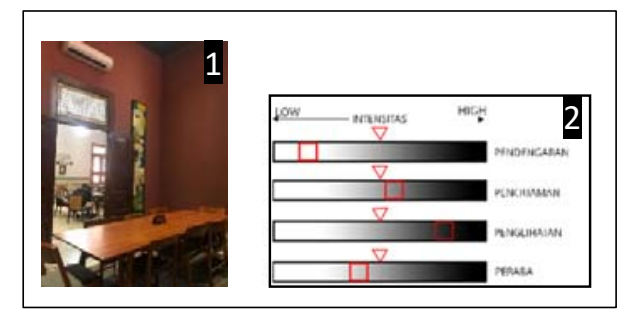

Gambar 7. Perspektif Area (1), Skema Slider Sensory yang Dirasakan di Titik B (2) Sumber: Dokumentasi Penulis (2020)

Setelah memasuki ruang makan 1 terdapat ruang makan 2 yang memiliki titik sudut pandang berupa titik $\mathrm{E}$ dan $\mathrm{F}$ yang menerapkan elemen interior yang dirasakan oleh panca indra pada gambar 7. Batasan-batasan aspek panca indra visual yang diterapkan ini meliputi ornamen, kompleksitas, dan misteri. Area tersebut dapat merasakan penerapan indra pendengaran dengan latar belakang musik dan aspek kebisingan. Penerapan panca indra penciuman yang diterapkan dengan aspek aroma pada area tersebut. Selain itu batasan panca indra peraba dengan menerapkan aspek suhu, material dan tekstur.

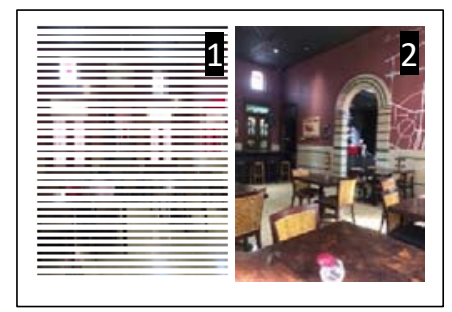

Gambar 8. Perspektif Area Titik E (1), Titik F (2) Sumber: Dokumentasi Penulis (2020)

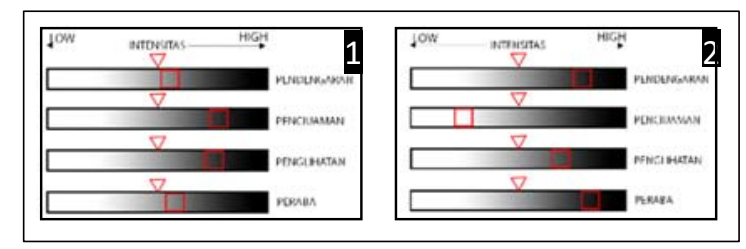

Gambar 9. Skema Slider Sensory yang Dirasakan di Titik E (1), Titik F (2) Sumber: Dokumentasi Penulis (2020)

Area terakhir kafe Tanamera yaitu smoking area, titik G dan $\mathrm{H}$ telah menerapkan elemen interior yang dipersepsikan oleh panca indra pengunjung sesuai dengan gambar 9. Hasil analisa panca indra pada 2 titik sudut pandang ini menerapakan batasan visual berupa ornamen, warna, kompleksitas, pencahayaan, dan misteri. Panca indra peraba di smoking area menerapkan aspek dimensi ruang, material dan tekstur, selain itu panca indra pendengaran juga diterapkan dengan aspek kebisingan dan latar belakang musik. Akan tetapi penerapan panca indra penciuman yang tidak diterapkan pada ruangan smoking. 


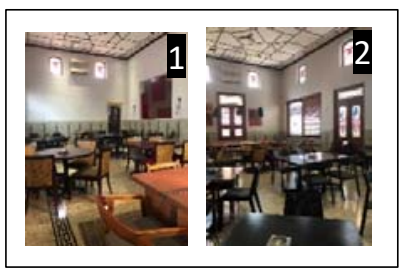

Gambar 8. Perspektif Area Titik F (1), Titik G (2) Sumber: Dokumentasi Penulis (2020)

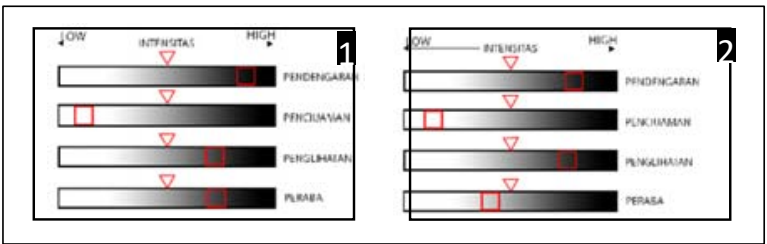

Gambar 9. Skema Slider Sensory yang Dirasakan di Titik F (1), Titik G (2) Sumber: Dokumentasi Penulis (2020)

\section{Analisa Komparasi Teori dengan Data Lapangan}

Melihat analisa data perbandingan tersebut, kafe Tanamera dengan titik sudut pandang A hingga $\mathrm{H}$ menerapkan material yang bervariasi pada elemen interior ruang, akan tetapi pada sudut pandang titik $\mathrm{H}$ penerapan material yang kurang teapt tersebut yang dapat mempengaruhi pengalaman panca indra pada pengunjung. Pengaturan suhu ruangan sangat perlu diperhatikan karena mempengaruhi pengalaman panca indra, titik $\mathrm{B}$ dan $\mathrm{C}$ telah menerapkan pengaturan suhu dan sirkulasi udara yang tepat pada elemen interior ruang. Titik A, D, E, F mengatur suhu ruangan dan kelembapan, akan tetapi daerah sudut pandang ini tidak terlalu merasakan pengaruh yang diberikan. Sedangkan pada titik G dan $\mathrm{H}$ sangat kurangnya pengaturan suhu pada elemen ruang area ini serta kurangnya sirkulasi udara pada dua titik sudut pandang ini

Aspek batasan indra peraba lainnya yaitu ditinjau dari teori dimensi ruang, titik A, B, C, F, $\mathrm{G}$ telah menerapkan jarak yang tepat untuk posisi duduk dan sirkulasi ruangan. Jarak antar pengunjung dan sirkulasi pada teori batasana dimensi ruang sangat mempengaruhi pengalaman panca indra. Akan tetapi titik D, E, H penerapan jarak dimensi ruang yang dirasakan masih kuran. Sehingga dapat disimpulkan bahwa pengalaman panca indra peraba di kafe Tanamera banyak dialami pada titik A, B, C, F, G. Pada titik lainnya yaitu D, E, H pengalaman panca indra yang diterapkan pada elemen interior masih kurang.

\section{KESIMPULAN}

Berdasarkan hasil analisis bahwa pengalaman panca indra memiliki peran besar bagi pengunjung dalam ruang interior. Setiap pengunjung kafe Tanamera memiliki pengalaman yang dirasakan berbeda sesuai dengan titik sudut pandang pengunjung berada. Pengalaman panca indra tersebut dapat dirasakan melalui batasan teori sensory yang berkaitan dengan penerapan 9 elemen interior di kafe Tanamera, yaitu ornamen, cahaya, warna, kompleksitas, misteri, aroma, bau, material dan tekstur, dimensi ruang, suhu, latar belakang musik, kebisingan.

Kafe Tanamera telah menerapkan pengalaman panca indra visual dan peraba yang memiliki peran banyak pada 9 elemen interior ruang pada bangunan heritage. Hal ini dapat dilihat pada penerapan indra visual terkait dengan elemen interior, warna coklat, hitam, dan 


\section{DPFín}

Vol. 5, No. 1, Juni 2020, pISSN 2527-2853, eISSN 2549-2985

merah yang merupakan warna dominan. Warna merah gelap membuat aktivitas begerak maju atau agresif, warna hitam pada plafon membuat ruang terasa hampa. Hal ini merupakan salah satu faktor mengurangi pengalaman panca indra pengunjung pada beberapa ruang. Warna coklat yang memberikan efek psikologis yang nyaman dan memberikan suasana heritage. Perpaduan warna merah gelap pada dinding dengan warna hitam pada plafon membuat suasana pada ruangan terasa gelap. Selain itu pencahayaan dengan recessed spotlight dan pendant lamp berwarna warm white pada ruangan dengan dinding berwarna merah gelap dan plafon berwarna hitam membuat ruangan terasa gelap dan efek psikologis yang diberikan dapat memperlambat efisiensi pekerjaan yang dirasakan pengunjung.

Pencahayaan recessed spotlight dan pendant lamp berwarna warm white pada area lain dengan warna ruangan yang cerah memberikan fokus visual pada ornamen atau desain konsep bangunan heritage, dan kenyamanan, serta memberikan suasana ruang. Cahaya putih hangat ini meningkatkan tingkat energi pengunjung dan juga memperbaiki suasana hati. Serta cahaya matahari pada siang hari pada kafe Tanamera ini dapat memicu tingkat kinerja pekerja, penjualan pada kafe, dan suasana hati pengunjung. Ornamen, kompleksitas, dan misteri yang dirasakan oleh panca indra visual memberikan kesan heritage/identitas pada budaya kolonial belanda seperti penggunaan ukiran pada dinding, plafon, pintu, serta perabot. Dekorasi ruang yang mendukung kesan bangunan heritage dengan dekorasi kuno yang memberikan kesan budaya. Penerapan elemen interior yang memiliki kesan budaya ini tidak hanya dirasakan secara visual, akan tetapi juga dirasakan dengan panca indra peraba. Penggunaan spotlight lamp yang memberikan detail pada material dan merasakan tekstur dengan sentuhan tidak langsung.

Penerapan elemen dekorasi memberikan pengalaman panca indra peraba dengan sentuhan langsung, selain itu menerapkan beberapa material yang memberi kesan hangat yaitu dengan material karpet. Serta penggunaan material karpet juga dapat menyerap suara sehingga mengurangi kebisingan dalam ruang. Bentuk dimensi ruang yang luas dengan tidak mengubah bentuk bangunan kafe ini, memberi kan pengalaman panca indra peraba pengunjung. Serta bentuk fasad bangunan luar yang tidak di ubah meberikan kesan budaya yang diberikan pada pengunjung sehingga mempengaruhi pengalaman panca indra visual. Bentuk bangunan heritage yang tidak diubah pada kafe Tanamera ini, dengan memiliki dinding yang tebal dapat meredam suara kebisingan dari luar bangunan kafe. Ruangan kafe juga telah mengontol suhu dengan sirkulasi udara, serta mengntrol kelembapan. Akan tetapi beberapa ruang Tanamera, sirkulasi udara dan control suhu ruangan yang diterapkan masih kurang baik sehingga mempengaruhi pengalaman panca indra peraba dan juga penciuman.

Aspek penciuman yang terdiri atas aroma dan bau, dengan sirkulasi udara yang kurang baik pada smoking area membuat asap rokok yang menjadi gangguan bau pada ruang tersebut. Aroma kopi yang diterapkan pada kafe memberikan identitas coffee shop dan memberikan memori kepada pengunjung. Aspek lainnya yang diterapkan adalah indra pendengaran yaitu pada aspek latar belakang musik dengan old song dan slow. Penerapan lagu pada ruangan kafe memberikan kenyamanan dan memberikan mood teretentu pada pengunjung yang merasakannya sehingga dapat melakukan aktivitas dalam suatu ruang dengan jangka waktu yang lama. Akan tetapi pada beberapa area masih belum terdapat latar belakang musik yang membuat ruang terasa hampa, serta masih terdapat kebisingan suara mesin AC, suara peralatan dapur dan mesin kopi, suara kondosif pengunjung pada area VIP dan teras. Penerapan elemen interior di kafe Tanamera ini tidak hanya dapat dipersepsikan oleh indra visual saja, namun dapat dirasakan panca indra peraba, penciuman, serta pendengaran. Hal ini dapat dilhat pada penggunaan elemen dekorasi berupa mesin kopi dengan cepat informasi yang diberikan 
ditangkap melalui visual, selanjutnya indra peraba, indra pendengaran, serta indra penciuman dapat dirasakan.

Proses analisa yang telah dilakukan dalam penelitian ini, dapat disimpulkan bahwa semakin banyak pengolahan elemen interior dalam ruang dapat memperkaya pengalaman panca indra yang dirasakan. Walaupun tanpa disadari pengunjung, seringkali pengalaman yang diterapkan telah memberikan pengaruh kepada konsumen ketika berada dalam ruangan. Alangkah baiknya pengalaman panca indra yang diberikan lebih dipertimbangkan secara lebih maksimal/ lebih peka pada perancangan elemen interior, sehingga memberikan kesan dan pengalaman yang baik oleh setiap orang yang merasakannya/ mengalami. Oleh sebab itu, desain pada semua ruang tidak hanya restoran dapat memberikan pengalaman ruang yang mengesankan, menarik bagi pengunjung.

\section{DAFTAR PUSTAKA}

Bhattacherjee, Anol (2012). Social science research: Principles, methods, and practices. South Florida: University of South Florida.

Ching, Francis DK., Binggeli Corky (2012). Interior Design Illustrated Second Edition. United States of America: Canada.

Herliana, Emmelia T., Hanan, Himasari (2016). Persepsi Masyarakat Terhadap Suasana Bangunan Kolonial yang Berfungsi Sebagai Fasilitas Publik.

Jaynes, J (1976). The Origin of Consciousness In The Breakdown Of The Bicameral Mind.

Kopec, Dak (2012). Enviromental Psychology for Design 2nd Edition. Canada: Fairchild Books.

Lindstrom, M (2005). Brand Senses. New York: Free Press.

Maas, J.B., Jayson, J.K., dan Kleiber, D.A (1974). Effect of Spectral Dofferences in Illumination on Fatigue. Journal of Applied Psyhology Vol. 59 No. 4.

Mahnke, Frank H., Rudolf H. Mahnke (1993). Color and Light in Man-made Enviroments. Van Nostrand Reinhold: New York.

Malnar, Joy M., Vodvarka Frank (2004). Sensory Design. United States of America: University of Minnesota Press.

Noviarini, Amanda P., Khasanah, Imroatul (2014). Analisis Pengaruh Experiental Marketing Terhadap Kepuasan Pelanggan Resto Semarang. Diponegoro Jurnal of Management. Vol. 3 No. 3.

Pallasmaa, J (2012). The Eyes of the Skin. United Kingdom.

Pocock, Douglas (1989). Sound and the Georapher. Journal of the Geographical Association. Vol. 74 No. 3.

Pradana, D (2017). Pemetaan Pola-Pola Brand Indentity Melalui Sensoris Indera Penciuman (Olfactory) Dalam Membangun Social Engagement Studi Olfactics pada Outlet Ritel di Mal-Mal di Jakarta.

Scott, Suzanne C (1993). Complexity and Mystery as Predictors of Interior Preference. Journal of Interior Design. Vol. 19 No. 1.

Sugiono (2009). Metode Penelitian Kuantitatif, Kualitatif, dan R\&D.

Wulandari, H (2014). Eksplorasi Pengalaman Panca Indera untuk Perancangan Interior. Dimensi Interior. Vol. 12 No. 2. 